\title{
Notes on oscillation of linear delay differential equations
}

\section{Božena Dorociaková* (i), Radoslav Chupáč and Rudolf Olach}

\author{
"Correspondence: \\ bozena.dorociakova@fstroj.uniza.sk \\ Department of Applied \\ Mathematics, University of Žilina, \\ Žilina, Slovak Republic
}

\begin{abstract}
This paper deals with the oscillation criteria for the linear delay differential equations. We present new sufficient conditions for the oscillation of all solutions of such equations. The results improve and complement some earlier ones in the literature.
\end{abstract}

MSC: 34K06; 34K11

Keywords: Oscillation; Delay differential equation; Sufficient conditions

\section{Introduction}

In this article we consider the linear delay differential equation

$$
x^{\prime}(t)+p(t) x(\tau(t))=0, \quad t \geq t_{0}
$$

where the functions $p, \tau \in C\left(\left[t_{0}, \infty\right),(0, \infty)\right), \tau(t)$ is nondecreasing, $\tau(t)<t$ for $t \geq t_{0}$ and $\lim _{t \rightarrow \infty} \tau(t)=\infty$.

Our aim is to establish new sufficient conditions for the oscillation of all solutions of Eq. (1). This problem has been recently investigated by many authors. See, for example, [1-14] and the references cited therein.

A continuously differentiable function defined on $\left[\tau\left(T_{0}\right), \infty\right)$ for some $T_{0} \geq t_{0}$ and satisfying Eq. (1) for $t \geq T_{0}$ is called a solution of Eq. (1). Such a solution is called oscillatory if it has arbitrarily large zeros. Otherwise, it is called nonoscillatory.

We will denote by $k$ the lower limit of the average

$$
\int_{\tau(t)}^{t} p(s) d s
$$

as $t \rightarrow \infty$, i.e.,

$$
k=\liminf _{t \rightarrow \infty} \int_{\tau(t)}^{t} p(s) d s,
$$

and constant $L$ is defined by

$$
L=\limsup _{t \rightarrow \infty} \int_{\tau(t)}^{t} p(s) d s
$$

(c) The Author(s) 2018. This article is distributed under the terms of the Creative Commons Attribution 4.0 International License (http://creativecommons.org/licenses/by/4.0/), which permits unrestricted use, distribution, and reproduction in any medium, provided you give appropriate credit to the original author(s) and the source, provide a link to the Creative Commons license, and indicate if changes were made. 
We refer the readers to the papers $[6,13]$ for the historical and chronological review of the results. We mention some results in the literature (cf. $[6,13])$ for the purpose of this article. In 1972 Ladas, Lakshmikantham, and Papadakis [11] proved that if the following holds

$$
L=\limsup _{t \rightarrow \infty} \int_{\tau(t)}^{t} p(s) d s>1
$$

then every solution of Eq. (1) oscillates.

In 1979 Ladas [10] and in 1982 Koplatadze and Chanturija [7] showed that the same conclusion holds if

$$
k=\liminf _{t \rightarrow \infty} \int_{\tau(t)}^{t} p(s) d s>\frac{1}{e} .
$$

We point out that if the inequality

$$
\int_{\tau(t)}^{t} p(s) d s \leq \frac{1}{e}
$$

holds eventually, then, according to a result in [7], Eq. (1) has a nonoscillatory solution.

It is obvious that there is a gap between conditions (2) and (3) when the limit

$$
\lim _{t \rightarrow \infty} \int_{\tau(t)}^{t} p(s) d s
$$

does not exist. How to fill this gap is an interesting problem which has been recently investigated by several authors, e.g., [1-6, 8, 9, 12-15].

In the case $0<k \leq 1 / e$, all conditions in the papers $[4-6,8,9,12-14]$ are dependent on $0<L<1$. The aim of this article is to establish such conditions for oscillation of solutions of Eq. (1) which are independent of $L$.

We assume for the analysis of asymptotic behavior of the function

$$
w(t)=\frac{x(\tau(t))}{x(t)}
$$

that Eq. (1) has a solution $x(t)$ which is positive for all large $t$.

In the second section we will use the next lemma by Jaroš and Stavroulakis [5].

Lemma 1.1 ([5]) Suppose that $k>0$ and Eq. (1) has an eventually positive solution $x(t)$. Then $k \leq 1 / e$ and

$$
\lambda_{1} \leq \liminf _{t \rightarrow \infty} w(t) \leq \lambda_{2}
$$

where $\lambda_{1}$ is the smaller and $\lambda_{2}$ is the greater root of the equation $\lambda=e^{k \lambda}$.

\section{Oscillatory properties}

In this section we will study the oscillatory properties of Eq. (1). 
Lemma 2.1 Let $x(t)$ be an eventually positive solution of Eq. (1) and $0<k \leq \frac{1}{e}$. Suppose that

$$
\liminf _{t \rightarrow \infty} \int_{\tau(t)}^{t} p(s) \exp \left(\lambda_{1} \int_{\tau(s)}^{\tau(t)} p(u) d u\right) d s>1-\frac{1}{\beta}
$$

where $\beta \in\left[\lambda_{1}, \lambda_{2}\right]$, and $\lambda_{1}$ is the smaller and $\lambda_{2}$ is the greater root of the equation $\lambda=e^{k \lambda}$.

Then

$$
\liminf _{t \rightarrow \infty} \frac{x(\tau(t))}{x(t)}>\beta
$$

Proof Let $t>t_{0}$ be large enough so that $\tau(t)>t_{0}$. Integrating (1) from $\tau(t)$ to $t$, we obtain

$$
x(\tau(t))=x(t)+\int_{\tau(t)}^{t} p(s) x(\tau(s)) d s .
$$

Let $0<\lambda<\lambda_{1}$. Then the function

$$
\varphi(t)=x(t) \exp \left(\lambda \int_{t_{0}}^{t} p(s) d s\right), \quad t \geq t_{1}
$$

is decreasing for appropriate $t_{1} \geq t_{0}$ (cf. $\left.[6,13]\right)$. Indeed by Lemma 1.1

$$
\frac{x(\tau(t))}{x(t)}>\lambda
$$

for $t \geq t_{2}$, where $t_{2} \geq t_{1}$ is sufficiently large, and consequently,

$$
0=x^{\prime}(t)+p(t) x(\tau(t))>x^{\prime}(t)+\lambda p(t) x(t)
$$

which implies $\varphi^{\prime}(t)<0$ for $t \geq t_{2}$. Substituting (6) into (5), we derive for $t \geq t_{2}$ that

$$
\begin{aligned}
& x(\tau(t))= x(t)+\int_{\tau(t)}^{t} p(s) \varphi(\tau(s)) \exp \left(-\lambda \int_{t_{0}}^{\tau(s)} p(u) d u\right) d s, \\
& x(\tau(t)) \geq x(t)+\varphi(\tau(t)) \int_{\tau(t)}^{t} p(s) \exp \left(-\lambda \int_{t_{0}}^{\tau(s)} p(u) d u\right) d s, \\
& x(\tau(t)) \geq x(t)+x(\tau(t)) \exp \left(\lambda \int_{t_{0}}^{\tau(t)} p(u) d u\right) \\
& \times \int_{\tau(t)}^{t} p(s) \exp \left(-\lambda \int_{t_{0}}^{\tau(s)} p(u) d u\right) d s, \\
& x(\tau(t)) \geq x(t)+x(\tau(t)) \int_{\tau(t)}^{t} p(s) \exp \left(\lambda \int_{\tau(s)}^{\tau(t)} p(u) d u\right) d s, \\
& 0 \geq x(t)+x(\tau(t))\left(-1+\int_{\tau(t)}^{t} p(s) \exp \left(\lambda \int_{\tau(s)}^{\tau(t)} p(u) d u\right) d s\right) .
\end{aligned}
$$


From (4) it follows that there exists a constant $c$ such that $c>1-\frac{1-\varepsilon}{\beta}$, where $0<\varepsilon<\beta[c-$ $\left.\left(1-\frac{1}{\beta}\right)\right] \leq 1$, and

$$
\liminf _{t \rightarrow \infty} \int_{\tau(t)}^{t} p(s) \exp \left(\lambda_{1} \int_{\tau(s)}^{\tau(t)} p(u) d u\right) d s \geq c>1-\frac{1-\varepsilon}{\beta} .
$$

Then, for $\lambda$ sufficiently close to $\lambda_{1}$, we get

$$
\int_{\tau(t)}^{t} p(s) \exp \left(\lambda \int_{\tau(s)}^{\tau(t)} p(u) d u\right) d s \geq 1-\frac{1-\varepsilon}{\beta}, \quad t \geq t_{3},
$$

where $t_{3} \geq t_{2}$ is sufficiently large. If it is not true, then for all $0<\lambda<\lambda_{1}$ we have

$$
\liminf _{t \rightarrow \infty} \int_{\tau(t)}^{t} p(s) \exp \left(\lambda \int_{\tau(s)}^{\tau(t)} p(u) d u\right) d s \leq 1-\frac{1-\varepsilon}{\beta}<c
$$

By letting $\lambda \rightarrow \lambda_{1}$, the last inequality leads to

$$
\liminf _{t \rightarrow \infty} \int_{\tau(t)}^{t} p(s) \exp \left(\lambda_{1} \int_{\tau(s)}^{\tau(t)} p(u) d u\right) d s<c
$$

This inequality contradicts (8). Thus we obtain from (7)

$$
\begin{aligned}
& 0 \geq x(t)-\frac{1-\varepsilon}{\beta} x(\tau(t)), \\
& 0 \geq 1-\frac{1-\varepsilon}{\beta} \frac{x(\tau(t))}{x(t)}, \\
& \frac{x(\tau(t))}{x(t)} \geq \frac{\beta}{1-\varepsilon}>\frac{(1-\varepsilon) \beta}{1-\varepsilon}=\beta, \quad t \geq t_{3} .
\end{aligned}
$$

Therefore, we have

$$
\liminf _{t \rightarrow \infty} \frac{x(\tau(t))}{x(t)}>\beta
$$

The proof is complete.

Theorem 2.1 Let $0<k \leq \frac{1}{e}$. Suppose that

$$
\liminf _{t \rightarrow \infty} \int_{\tau(t)}^{t} p(s) \exp \left(\lambda_{1} \int_{\tau(s)}^{\tau(t)} p(u) d u\right) d s>1-\frac{1}{\lambda_{2}} .
$$

Then all solutions of Eq. (1) oscillate.

Proof Assume that Eq. (1) eventually has a positive solution $x(t)$. It follows from Lemma 2.1 that

$$
\liminf _{t \rightarrow \infty} \frac{x(\tau(t))}{x(t)}>\lambda_{2}
$$

This contradicts the result of Lemma 1.1 and completes the proof of the theorem. 
Theorem 2.2 Let $0<k \leq \frac{1}{e}$. Suppose that there exists $\gamma \in\left(\lambda_{1}, \lambda_{2}\right)$ such that

$$
\begin{aligned}
& \liminf _{t \rightarrow \infty} \int_{\tau(t)}^{t} p(s) \exp \left(\lambda_{1} \int_{\tau(s)}^{\tau(t)} p(u) d u\right) d s>1-\frac{1}{\gamma}, \\
& \liminf _{t \rightarrow \infty} \int_{\tau(t)}^{t} p(s) \exp \left(\gamma \int_{\tau(s)}^{\tau(t)} p(u) d u\right) d s>1-\frac{1}{\lambda_{2}} .
\end{aligned}
$$

Then all solutions of Eq. (1) oscillate.

Proof Assume that Eq. (1) has an eventually positive solution $x(t)$. By Lemma 2.1, condition (9) implies that

$$
\liminf _{t \rightarrow \infty} \frac{x(\tau(t))}{x(t)}>\gamma
$$

With regard to condition (10) and repeating the procedure as in the proof of Lemma 2.1, we get

$$
\liminf _{t \rightarrow \infty} \frac{x(\tau(t))}{x(t)}>\lambda_{2}
$$

This contradicts the result of Lemma 1.1. The proof is complete.

In the next example we observe the case $k=1 / e$. Then $\lambda_{1}=\lambda_{2}=e$.

Example $([6,13])$ Consider the linear delay differential equation

$$
x^{\prime}(t)+p x\left(t-a \sin ^{2} \sqrt{t}-\frac{1}{p e}\right)=0, \quad t \geq t_{0},
$$

where $p>0, a>0$.

Then

$$
\begin{aligned}
k & =\liminf _{t \rightarrow \infty} \int_{\tau(t)}^{t} p d s=\liminf _{t \rightarrow \infty} p\left(a \sin ^{2} \sqrt{t}+\frac{1}{p e}\right) \\
& =\liminf _{t \rightarrow \infty}\left(p a \sin ^{2} \sqrt{t}+\frac{1}{e}\right)=\frac{1}{e} .
\end{aligned}
$$

We get

$$
\begin{aligned}
\int_{\tau(t)}^{t} p \exp \left(e \int_{\tau(s)}^{\tau(t)} p d u\right) d s & =p \int_{\tau(t)}^{t} \exp (p e(\tau(t)-\tau(s))) d s \\
& =p \exp (p e \tau(t)) \int_{\tau(t)}^{t} \exp (-p e \tau(s)) d s \\
& =p \exp (p e \tau(t)) \int_{\tau(t)}^{t} \exp \left(-p e\left(s-a \sin ^{2} \sqrt{s}-\frac{1}{p e}\right)\right) d s \\
& =e p \exp (p e \tau(t)) \int_{\tau(t)}^{t} \exp (-p e s) \exp \left(\text { ape }^{2} \sin ^{2} \sqrt{s}\right) d s
\end{aligned}
$$


Then we have

$$
\begin{aligned}
& \liminf _{t \rightarrow \infty} \operatorname{ep} \exp (p e \tau(t)) \int_{\tau(t)}^{t} \exp (-p e s) \exp \left(\text { ape } \sin ^{2} \sqrt{s}\right) d s \\
& >\liminf _{t \rightarrow \infty} \operatorname{ep} \exp (\operatorname{pe\tau }(t)) \int_{\tau(t)}^{t} \exp (-p e s) d s \\
& =\liminf _{t \rightarrow \infty} \exp (p e \tau(t))(\exp (-p e \tau(t))-\exp (-p e t)) \\
& =\liminf _{t \rightarrow \infty}(1-\exp (p e(\tau(t)-t)))=\liminf _{t \rightarrow \infty}\left(1-\exp \left(- \text { ape } \sin ^{2} \sqrt{t}-1\right)\right) \\
& =\liminf _{t \rightarrow \infty}\left(1-\frac{1}{e} \exp \left(- \text { ape } \sin ^{2} \sqrt{t}\right)\right)=1-\frac{1}{e} .
\end{aligned}
$$

We conclude that

$$
\liminf _{t \rightarrow \infty} \int_{\tau(t)}^{t} p \exp \left(e \int_{\tau(s)}^{\tau(t)} p d u\right) d s>1-\frac{1}{e}
$$

and by Theorem 2.1 all solutions of Eq. (11) oscillate.

We point out that the results in $[6,13]$ are dependent on the constant $0<L<1$, while our results do not depend on the constant $L$.

\section{Acknowledgements}

The authors gratefully acknowledge the Scientific Grant Agency VEGA of the Ministry of Education of Slovak Republic and the Slovak Academy of Sciences for supporting this work under the Grant No. 1/0812/17. The authors would like to thank the anonymous referees for their valuable comments.

\section{Competing interests}

The authors declare that they have no competing interests

\section{Authors' contributions}

The authors have made the same contribution. All authors read and approved the final manuscript.

\section{Publisher's Note}

Springer Nature remains neutral with regard to jurisdictional claims in published maps and institutional affiliations.

Received: 17 January 2018 Accepted: 21 April 2018 Published online: 04 May 2018

\section{References}

1. Baštinec, J., Berezansky, L., Diblík, J., Šmarda, Z.: On the critical case in oscillation for differential equations with a single delay and with several delays. Abstr. Appl. Anal. 2010, Article ID 417869 (2010)

2. Diblík, J., Růžičková, M., Šutá, Z.: Asymptotical convergence of the solutions of a linear differential equation with delays. Adv. Differ. Equ. 2010, Article ID 749852 (2010)

3. Diblík, J., Svoboda, Z., Šmarda, Z.: Explicit criteria for the existence of positive solutions for a scalar differential equation with variable delay in the critical case. Comput. Math. Appl. 56(2), 556-564 (2008)

4. Erbe, L.H., Zhang, B.G.: Oscillation for first order linear differential equations with deviating arguments. Differ. Integral Equ. 1, 305-314 (1988)

5. Jaroš, J., Stavroulakis, I.P.: Oscillation tests for delay equations. Rocky Mt. J. Math. 29, 139-145 (1999)

6. Kon, M., Scifas, Y.G., Stavroulakis, I.P.: Oscillation criteria for delay equations. Proc. Am. Math. Soc. 128, 2989-2997 (2000)

7. Koplatadze, R.G., Chanturija, T.A.: On oscillatory and monotonic solutions of first order differential equations with deviating arguments. Differ. Uravn. 18, 1463-1465 (1982) (Russian)

8. Koplatadze, R.G., Kvinikadze, G.: On the oscillation of solutions of first order delay differential inequalities and equations. Georgian Math. J. 1,675-685 (1994)

9. Kwong, M.K.: Oscillation of first order delay equations. J. Math. Anal. Appl. 156, 274-286 (1991)

10. Ladas, G.: Sharp conditions for oscillations caused by delays. Appl. Anal. 9, 93-98 (1979)

11. Ladas, G., Lakshmikantham, V., Papadakis, L.S.: Oscillations of higher-order retarded differential equations generated by the retarded arguments. In: Delay and Functional Differential Equations and Their Applications, pp. 219-231. Academic Press, New York (1972) 
12. Philos, C.H.G., Sficas, Y.G.: An oscillation criterion for first order linear delay differential equations. Can. Math. Bull. 41, 207-213 (1998)

13. Sficas, Y.G., Stavroulakis, I.P.: Oscillation criteria for first-order delay equations. Bull. Lond. Math. Soc. 35, 239-246 (2003)

14. Yu, J.S., Wang, Z.C., Zhang, B.G., Qian, X.Z.: Oscillations of differential equations with deviating arguments. Panam. Math. J. 2, 59-78 (1992)

15. Diblík, J., Kúdelčíková, M.: Existence and asymptotic behavior of positive solutions of functional differential equations of delayed type. Abstr. Appl. Anal. 2011, Article ID 754701 (2011)

Submit your manuscript to a SpringerOpen ${ }^{\odot}$ journal and benefit from:

- Convenient online submission

Rigorous peer review

- Open access: articles freely available online

- High visibility within the field

- Retaining the copyright to your article

Submit your next manuscript at $\boldsymbol{\nabla}$ springeropen.com 